\title{
TOURISM ARCHITECTURE AS A THREAT TO HERITAGE IDENTITY IN THE VALLEYS OF THE HIGH ATLAS IN MOROCCO
}

\author{
J. Asencio Juncal ${ }^{1}$, J.M. Lopez-Osorio ${ }^{1,}{ }^{*}$, C.J. Rosa Jiménez ${ }^{1}$ \\ ${ }^{1}$ Art and Architecture Department, University of Malaga, Malaga, Spain - (juncal, lopezosorio, cjrosa)@uma.es
}

Commission II - WG II/8

KEY WORDS: High Atlas, Dadès, Mgoun, Tourism architecture, Earthen architecture, Vernacular heritage, Berber decoration

\begin{abstract}
:
Despite being a major activity in the economy of the pre-Sahara valley of the High Atlas in Morocco, tourism can also threaten the conservation of the identity values of the architectural heritage of the region. The adaptation of many traditional buildings for tourist use or the construction of new accommodation incorporating traditional language into their structure or decorative repertoire does not always help to strengthen the vernacular values of original architecture. The starting point of this research is the typological definition of this architecture, mostly in aspects relating to the symbolic and ornamental elements of traditional dwellings in the valleys of the Dadès and of the Mgoun, its main tributary. The processes of evolution and transformation from the second half of the 20th century are then described, along with the risks from the tourist boom which has been affecting the region in recent years. In order to study this phenomenon twelve examples of tourist accommodation were selected to analyse the formal language and decorative resources used, in terms of heritage, but also from the perspective of the reinterpretation of architectural symbols in the context of acculturation. This theory considers dynamic cultural exchanges between tourism and the receiving society to be positive.
\end{abstract}

\section{INTRODUCTION}

\subsection{Territorial approach}

This research was carried out in the pre-Sahara region of southern Morocco, in the strip located between the high peaks of the High Atlas and the Sahara desert. The area under study focuses on the Dadès oued or river, particularly the valley of its main tributary, Mgoun oued. This river is born in the peaks of a mountain massif $4,071 \mathrm{~m}$ high and covers a vast territory over $100 \mathrm{~km}$ long to join the Dadès in Kelaat M'Gouna.

\subsection{Urban and architectural definition}

This territorial context has seen the development of a unique habitat around agricultural terrain, originally made up of collective or individual dwellings, all fortified. These small groups evolved over time into the current settlements located by the oasis (Ar. douar). The most representative historic typologies are the fortified village (Ar. qsar), the fortified dwelling (Br. tighremt) and the fortified collective granary (Br. ighremt).

The origins of this architecture are associated with the settlement process of the nomadic population which began in the 17th century, probably coinciding with the foundation of the oasis (Jacques-Meuniè, 1962).

The urban and architectural configuration shows a need for defence against the neighbouring tribes. The massive compact building was a defence mechanism whose wealth of decorations expressed a degree of social and political power. "All the architecture of the oasis is fortified. The delicate silhouettes of these buildings, so beautiful to contemplate, do not evoke any idea of peace. They must present inhabitants from attack and resist sieges" (Terrasse, 1938).
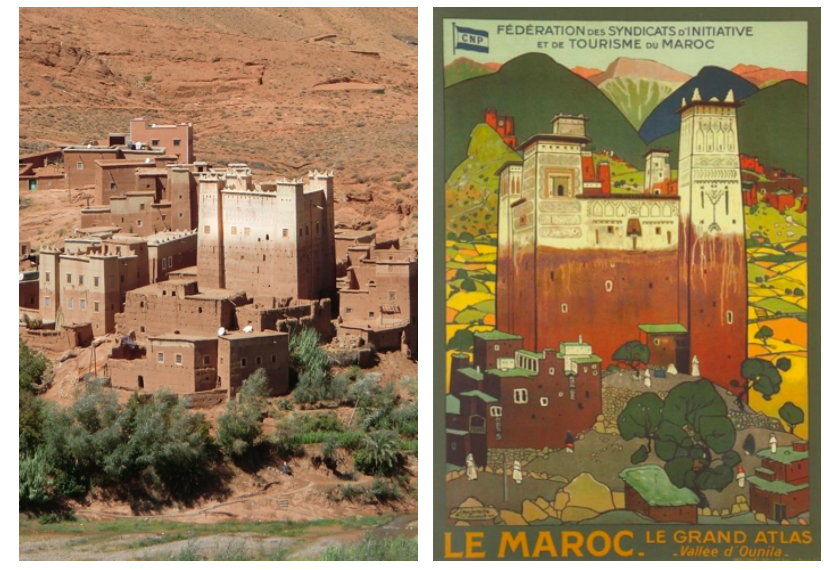

Figure 1. Left: Tighremt Aït Kho Haddou (L'hot). Right: Tourist poster of the "Fédération des syndicats d'initiative et de tourisme du Maroc". Jacques Majorelle, 1923.

\section{DECORATIVE FORM, MATERIAL AND REPERTOIRE OF FORTIFIED DWELLINGS}

The fortified dwelling, referred to hereafter both as tighremt, using the Berber name (Br.) and Kasbah, the generic name in Arabic (Ar.), is the most frequent historic type. These types of dwellings are still found in the douars or new towns, where they stand out for their massive constructions and tall towers. These fortified dwellings incorporated square floor plans and slightly pyramid-shaped towers, usually located on the corners projecting from the façades, above the terrace level. In traditional models, walls were built with rammed earth on the lower levels, whose façades had few openings for the purposes of defence. The upper sections of the towers and the walls of the

* Corresponding author 
terraces were built with adobe bricks arranged in different planes to form geometrical ornaments. These decorated walls were rendered with light-coloured earth or lime or gypsum mortars, creating a stark chromatic contrast between the raw earthen walls of the lower sections and the finishes of towers and crowning. At present these finishes have disappeared from the older buildings. However, they are still preserved in many fortified dwellings dating from the early 20th century, such as the Tighremt Ait Kho Haddou, in L'hot douar, in the centre of the valley of Mgoun. Another example of this tradition can be found in a Jacques Majorelle painting of a tighremt in the Ounila valley, used in 1923 as the image for a tourist poster for Morocco (Figure 1).

Although based on similar geometrical diagrams (Mimó, 1996), the decorative motifs are diverse and are found in the different valleys of southern Morocco. The more elaborate ones can be found in the Skoura oasis, $50 \mathrm{~km}$ from the Mgoun valley, and in the Tafilalt region, by the Ziz oued.

When describing the region Terrasse highlights that decoration is simpler in the Dadès and Mgoun regions, as large friezes and panels are infrequent, simple motifs such as points placed in the shape of triangles or crosses can be found. In his book Kasbas berbères de l'Atlas et des oasis (1938) the author presents a series of photographs of fortified dwellings in the Mgoun, most of which no longer exist, displaying subtle decorations with motifs dispersed around the walls and some friezes around the windows.

Jacques-Meunié, in her publication "Architectures et Habitats du Dadès" (1962), provides a detailed study of the more common decorative elements in the region, highlighting blind arches, which were used both to form friezes on the crownings of the façade and in the main details of the upper sections of the towers (Figure 2).

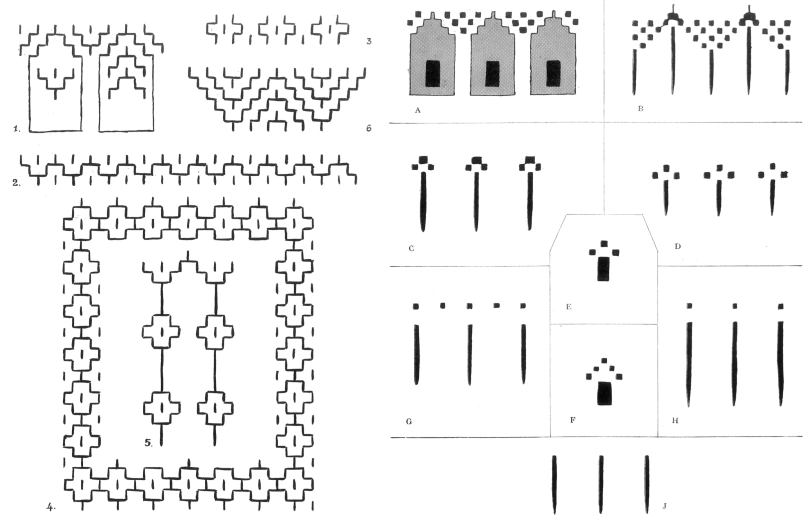

Figure 2. Left: Decorative motifs in Kelaat M'Gouna. Right: Progressive simplification of a frieze with arches. Source: Jacques-Meunié, 1962.

The backgrounds of these arches feature a wide range of motifs with different geometrical shapes although it is also common for the backgrounds to be plain, with a simple ventilation embrasure. Other recurring motifs include sawtooth borders, borders with rhomboids or half rhomboids, the hands of Fatima and cross-shaped motifs made up of four adobe bricks with a central opening evoking a flower, usually a rose.

Jacques-Meunié also carries out a chronological classification of the decorations found in the Dadès valley, proposing three eras or stages based on the form, technique, ornamental figures and state of conservation. In the first era (1750-1850) the essential characteristics of the decoration repertoire are defined, both for collective dwellings and for family homes, and most of the examples are located in the Skoura oasis.

In the second era (1850-1900) there is a particular emphasis on the development of fortified dwellings, incorporating the tall towers on the façade walls, finished off with small arch friezes. The researcher includes in this period the Tighremt Aït Aicha, located in the mountains in the village of Bou Taghrar, and also a photograph in which it can be seen a tower with rich decoration that conserves the white rendering (Figure 3). At present there is a fortified dwelling with the same name on this village (Figure 4); two of its towers are still standing at their original height and the geometrical reliefs that presents are very similar but not exactly as those on the Jacques-Meunié photograph.

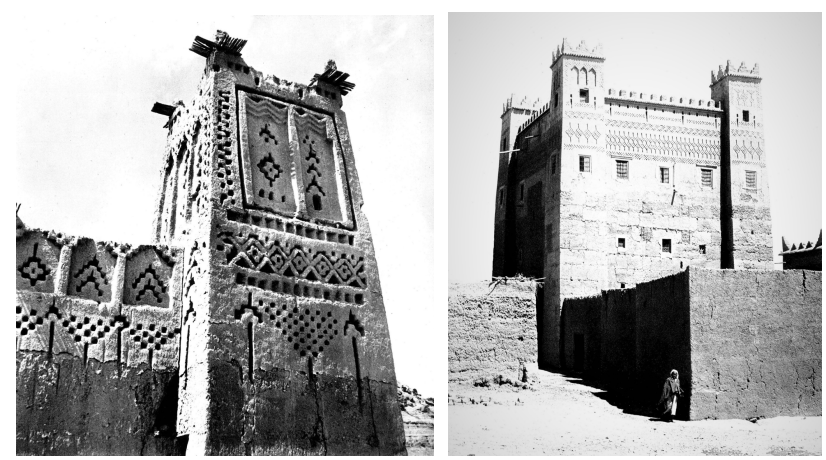

Figure 3. Left: Tighremt Aït Aicha (Bou Taghrar). Right: Tighremt Aït Said (Kelaat M'Gouna). Fuente: Jacques-Meunié, 1962.

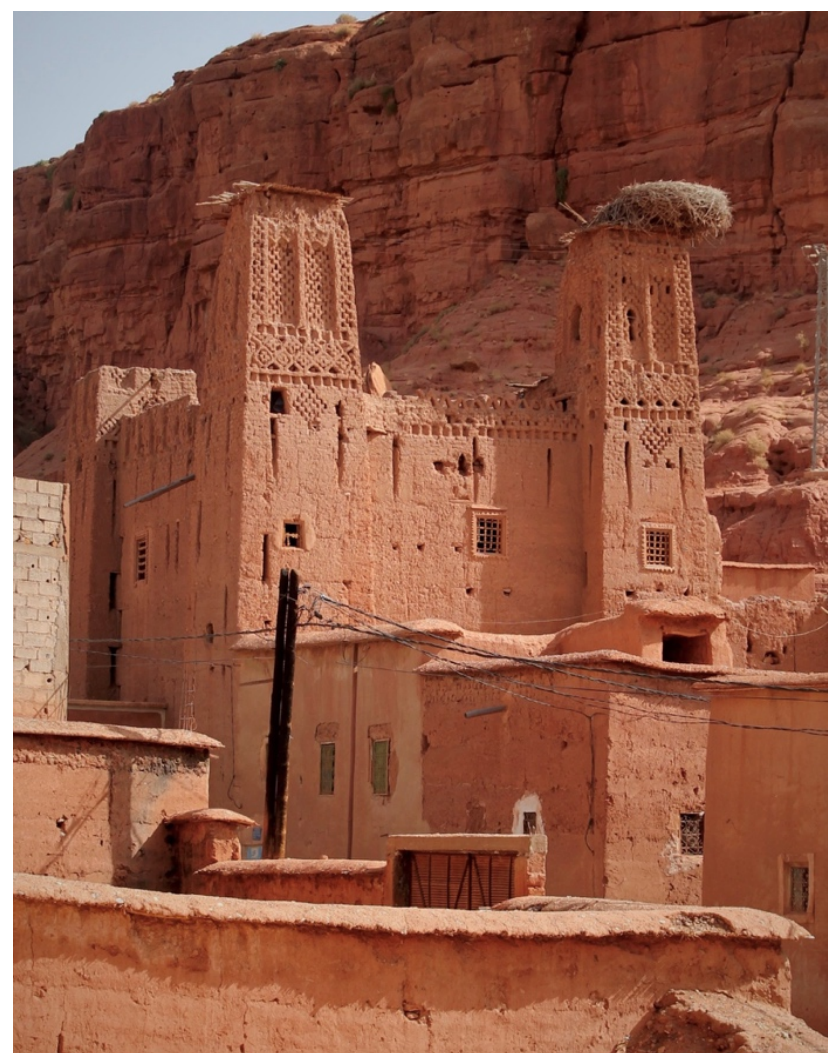

Figure 4. Tighremt Aït Aicha (Bou Taghrar), 2016. 
In the third era (1900-1940), decoration was gradually reduced and the massive constructions went on to incorporate larger format openings, coinciding with the peace process in the territories under the French protectorate. One of the buildings included in this period is the Tighremt Ait Said (Figure 3), built circa 1935 in Kelaat M'Gouna.

The building has motifs characteristic of the decorative repertoire, although much of the relief and depth of the arches has been lost. During this time the geometry and position of the adobes was gradually greatly simplified, with the loss of emphasis and reliefs with the passing of time. This was the case of the arch friezes finishing off walls and towers, which eventually became simple vertical slits (Figure 2).

Equally, the decline of decorative elements also affected the definition of the execution technique itself, as the geometrical combinations of earth-rendered adobe eventually disappeared.

The shape was conserved partly through simulating with incisions or slits in the thick layers of earth rendering which, in this period, also covered the rammed earth walls (Figure 5).

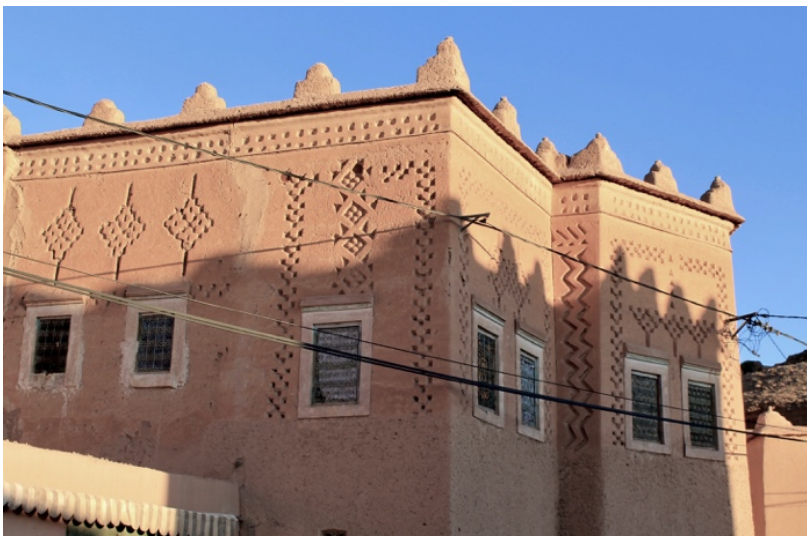

Figure 5. Engraved wall decoration near Kelaat M'Gouna.

\section{EVOLUTION AND TRANSFORMATION OF ARCHITECTURE IN THE SECOND HALF OF THE 20TH CENTURY}

The social and political changes which followed Morocco's independence from France in 1956 and the emigration in the following decades affected the south of Morocco especially.

This territory had been left behind in many of the modernization processes seen in the rest of the country, and was plunged into clear economic recession after the definitive disappearance of the social organization and tribal structure through which oasis architecture had come to be.

The abandonment of the ksar and tighremt due to the limitations of habitability and the loss of prestige of earthen architecture brought with them a transformation process in architecture which materialized as a change of typology and the use of new construction materials, mainly and reinforced concrete.

However, this phenomenon of change is not definitive or irreversible as some of the forms remain and the traditional constructive techniques are conserved. In the Mgoun valley dwellings with rammed earth walls continue to be built (LópezOsorio et al., 2012), using wood and reed for the floors and ceilings.

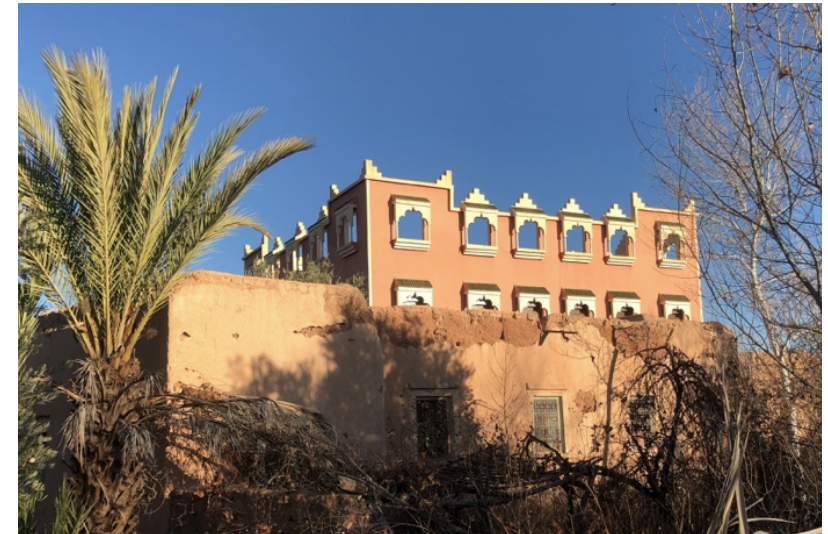

Figure 6. Contemporary dwelling near Kelaat M'Gouna.

In contrast, the mortar blocks and concrete structure recognize in their form the legacy of tradition, integrating into urban contexts where the chronology and typological evolution of the dwellings can be identified. "When observing the landscape of the valley at present, we do not see a place anchored in the past. Instead, the built landscape shows a variety of constructive types, past and present, which have evolved over time, although with the same genetic code"' (Díaz et al., 2012).

These transformations can be analysed based on the characteristic model of the tighremt, described above, and simplifying its forms until the towers and most of the decoration disappear. The original architectural type, which stands alone, is finely takes the form of earthen domestic architecture of simple volumes, having gone through different typologies in the stages of evolution.

In the final evolution phase, when introducing cement blocks and concrete into the Dadès and Mgoun valleys, an interesting phenomenon occurs with the recovery of the form of the old fortified dwellings, aiming to evoke the identity symbols of the historic type. In many buildings from recent decades we find simulations of towers on corners, executed by raising the wall of the terrace, finishing it off with merlons, which here are purely decorative (Figure 6). Despite the staging with postmodern elements this phenomenon shows a clear intention on the part of the local population to recognize architectural heritage.

\section{THE TOURIST PHENOMENON, ACCULTURATON AND LOSS OF IDENTITY}

In the field of anthropology there is widespread debate on the interferences between tourism and the receiving societies, resulting in different stances. The most critical defined this relationship as a "source of pollution and cultural destruction" (Palou, Mancinelli, 2016), in opposition to a more optimistic vision describing them as a positive cultural exchange through the theory of acculturation. This stance acknowledges that a society is not static but is in constant evolution and its changes, whatever the origin of the transforming agent, are one more element to be factored into the equation.

The tourist phenomenon has a great effect on the pre-Sahara valleys, specifically the Dadès valley, since the establishment of the "Kasbah Route" as a mass tourism product. "It is a phenomenon which produces, transforms and even causes the disappearance of certain signs of a culture" (Natoli et al., 2015, p. 537). This affects many levels, including the architecture of tourism and the entire style and decoration repertoire which 
comes with it as developers must satisfy the preconceived images held by the tourists and based on clichés, in order to attract customers. "In a globalized society where everyone wants to take part in the tourist market it seems that the latest generation holiday tourism, that of developing countries, tends to dissolve the place to replace it with the fiction of architecture" (Pié, Rosa, 2013).

In the Dadès valley, this dynamic, understood in the broadest sense, involves the standardization of style, abandoning the unique aspects of each area. The new architectures of tourism thus become driving forces for a new situation which recovers past memories of a general nature, rescuing only the most recognizable signs and icons of traditional buildings. On other occasions new identities are created or more recent cultural phenomena are used. In southern Morocco the recent iconographic explosion of the movement for the defence of the Amazigh culture, which has historically been at the receiving end of major repression, is representative of this. These secular symbols of Berber origins have now been incorporated into the decorative repertoire of tourist architecture. "Identities are a new tourist incentive, also adopted by tour operators and the Moroccan authorities in change of tourism development" (OiryVaracca, 2014).

However, the spatial formalization of these architectures of this form of use is very different to the autochthonous one, transforming the existing landscape with its single understandable vision into a more complex reading, often full of contradictions which could lead to a misconception of a traditional habitat among the new tourists.

\section{TOURISM ARCHITECTURE: A DOCEN OF CASES STUDIES}

As analysed in previous sections, the architectures of tourism are contributing to the construction of a collective imagery capable of introducing new identities among the local population. Tourist accommodation makes use of formal and decorative references from a different age, appropriating the language characteristic of fortified dwellings, or in more extreme cases, creating a new repertoire of icons to redefine the symbols of power in place until that point.

This dynamic transcends the frontiers of tourist accommodation to reach the rest of new constructions, with the use of decorative elements increasing in domestic architecture and institutional buildings. This is therefore a process of folklorization of architecture based on an unusual use of decorative elements out of context which occasionally uses a repertoire that is unprecedented or foreign to the region. In order to understand this phenomenon in the area under study in this research twelve establishments from among over seventy were studied. All of them are often visited by tourists as they are located beside the busy N-10 road or "Kasbah Route". In all cases, this accommodation is held in high esteem, although not all of them are engaged with the aspects examined in this study, such as the strengthening of local cultural identity, architectural integration into surroundings or contribution to the conservation of heritage.

An initial block presents three examples of traditional buildings adapted to tourist use, examining the transformation process. The second block is comprised of nine different examples of newly built accommodation, analysing formal and decorative language use.

\subsection{Traditional buildings restored for tourist use}

The maison d'hôtes "Kasbah Aït Ben Moro" (Figure 7) is a notable example of a heritage building adapted for tourist use. The original fortified dwelling, built in the 18th century, changed use in 1999 thanks to a Spanish developer.

The work affected some floors and the finish on the eaves of the towers, which were rendered using local techniques and materials. In addition, some openings were added on the façade, necessary to the new use, and all the original rammed earth walls were rendered; nevertheless, the building was "very carefully renovated in line with tradition" (Popp, 2008).

Over the years, new elements necessary for tourist activity have been added to the original construction, all respectfully executed using traditional materials and a suitable language which displays subtle differences from the original building.

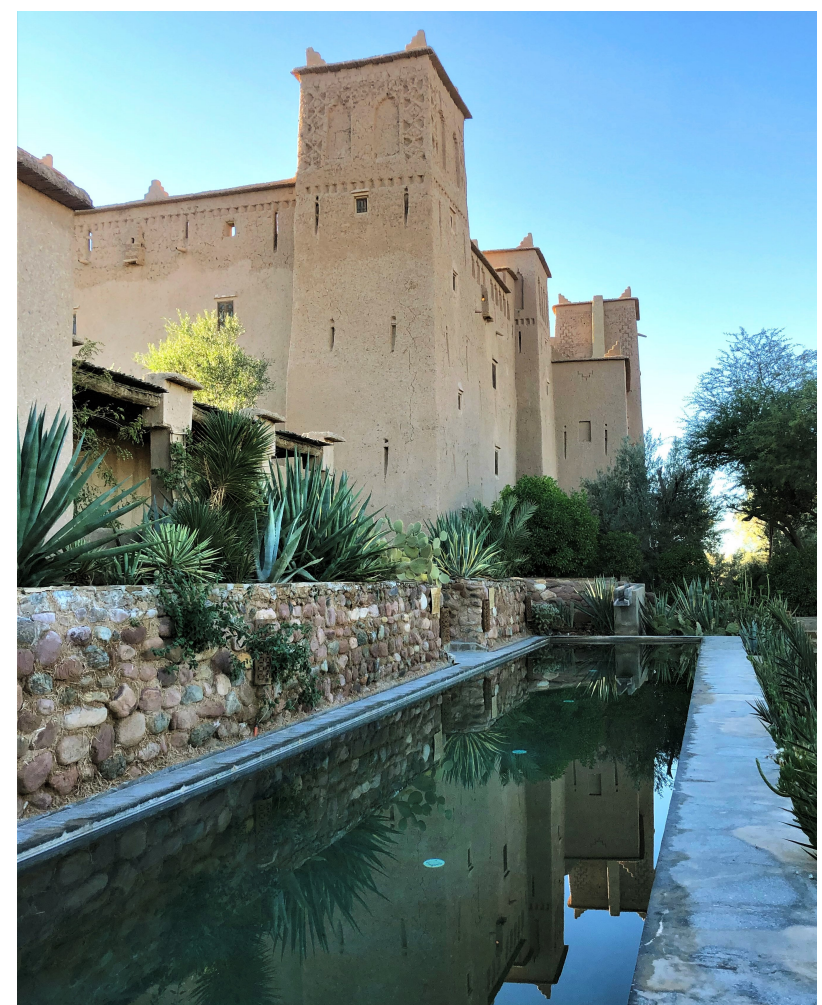

Figure 7. "Kasbah Aït Ben Moro", Taskoukamt, Skoura.

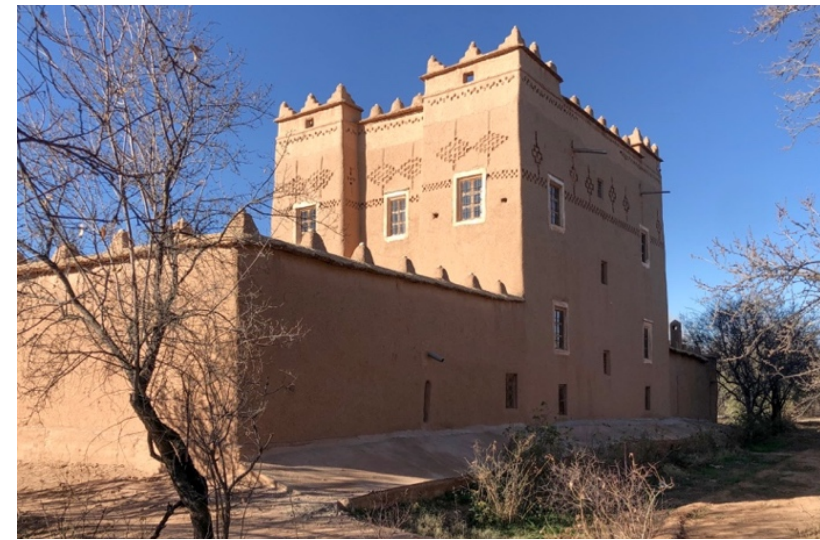

Figure 8. "Kasbah Aït Moussa”, Kelaat M'Gouna. 
The maison d'hôtes "Kasbah Aït Moussa" (Figure 8) is an initiative executed by local residents, although French specialists worked on its concept and design. This is a wellexecuted example of a respectful intervention in a fortified dwelling built in the early 1900s in the oasis of Kelaat M'Gouna. The building has undergone minimal interventions to transform it into tourist accommodation, respecting the original structure and simple decoration. Equally, the complementary buildings added around it to complete the programme were executed following local constructive tradition, although their simple language sets them apart from the original building. This is a good example of the recovery of an original structure.
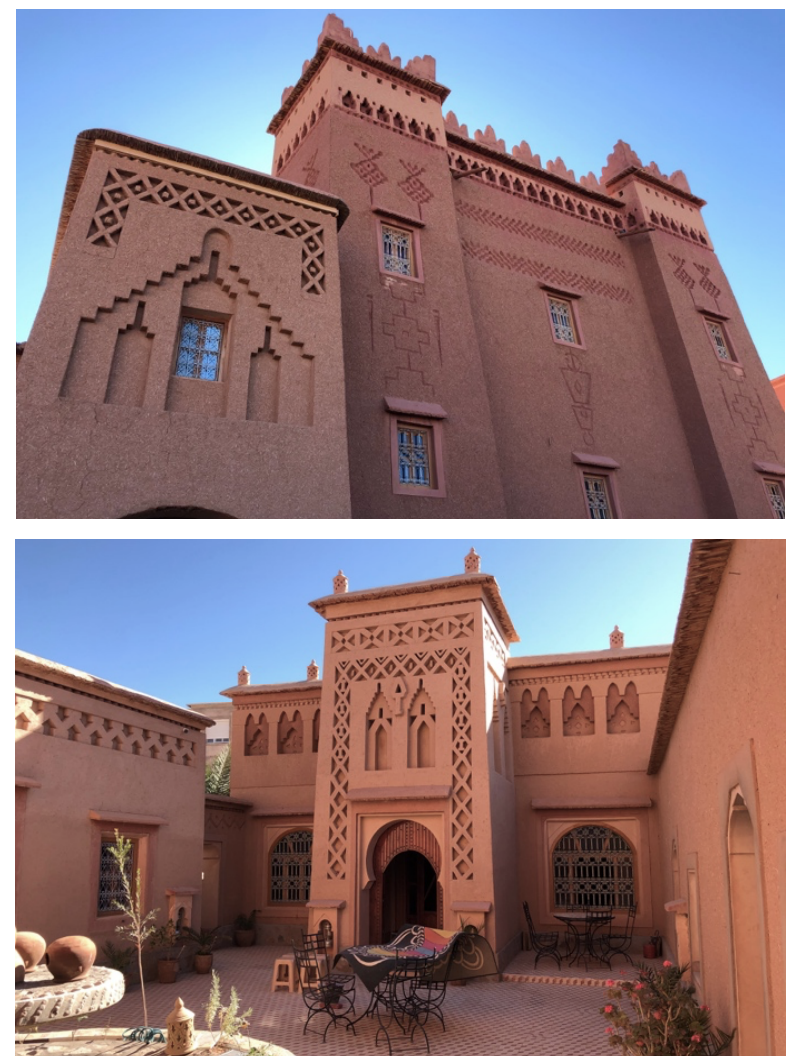

Figures 9 and 10. "Kasbah Aït Kassi”, Khemis Dadès.

The tourist accommodation "Kasbah Aït Kassi" (Figures 9-10) is located in the famous Tighremt Aït Kassi, built around 1920 during the period of pacification of the French protectorate, when the defensive needs were less. This is why it incorporates rather large windows on its façade, making it an optimal building for adaptation to tourist use. Nevertheless, some transformations have been made for this change in use. These are both functional and aesthetic and it is worth noting especially the incorporation of decorative elements using sgraffito techniques on a reddish earth mortar rendering applied to the façades. Also worth noting is the prominent language incorporated into the successive extensions or completions added to the original building (Figure 10). It was in these new pavilions that important work was carried out on the simple ornamentation, which exceeded that of the original tighremt in both repertoire and size. This is a very interesting case of the evolution of tourist architecture based on an independent original element with a simple configuration and modest decoration, taking on a complex final form made up of the addition of numerous volumes in which the decoration repertoire has become increasingly important, both formally and conceptually. This is a unique case which could be described as hyper-real architecture where, working with tradition, its code of symbols is reinterpreted in order to create a scene which to the eyes of the non-expert tourists can seem appealing. In any case, it should be noted that the decorative repertoire added, charged with Berber iconography, is a unique example of a deliberate demonstration on the part of its owners, who are from the region, showing a marked cultural, social and political trend.

\subsection{Newly built tourist accommodation}

This second block is made up of nine new constructions. The first five examples have mostly used traditional materials such as rammed earth, wood and reed floors and ceilings, reed eaves and adobe cornices, combining structural elements with hidden concrete reinforcements, in order to comply with the building regulations for tourist accommodation. The four remaining buildings mostly and manifestly used reinforced concrete as the main structural system.

The maison d'hôtes "Dar Jnan Tiaoura" (Figure 11) is presented as a traditional tighremt with several sets of towers raised up high. The main structure is in raw rammed earth following the local technique, introducing structural reinforcements in reinforced concrete. The decorative elements of façades, using adobe, are part of the traditional repertoire: arches, geometrical friezes, merlons, etc., although other less common elements such as series of windows with horseshoe arches on façades or projecting volumes on the main façades are introduced. The result is an interesting example of the uses of traditional constructive materials and decorative resources which, although they at times appear out of scale and context, manage to attract tourists with little knowledge of the local architecture.

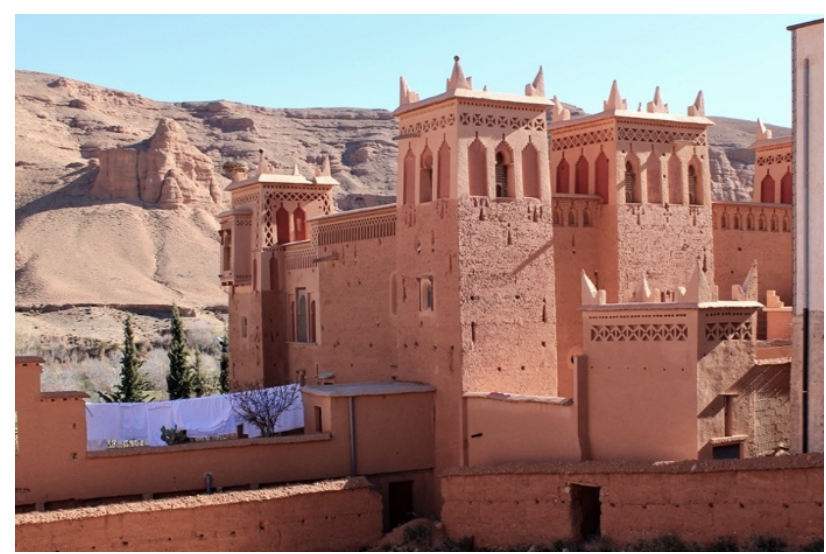

Figure 11. "Dar Jnan Tioura", Tamellalt.

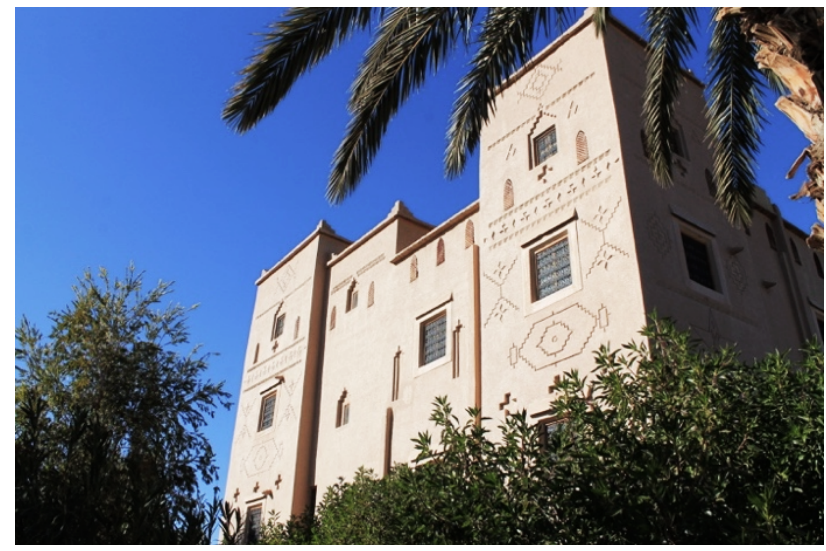

Figure 12. "Kasbah Ait Ben Damiette", Ouled Ali-Khamsa. 
The "Kasbah Ait Ben Damiette" (Figure 12), tourist accommodation run by a French family resident in Morocco, is on the site of an old fortified building which was in ruins. The poor condition of the walls, which could not withstand the load of new construction, meant it had to be demolished. The new building has followed the traditional layout of the tighremt, with four corner towers attached to smaller volumes at the back. The decoration which in traditional buildings was more prominent on the upper parts of the walls is organized here throughout the façades, with drawings engraved in earth mortar. This is an example where decoration is not greatly developed but rather is characterized by the free representation of symbolic elements, most notably the introduction of a symbol merging the star from the Moroccan flag, representing Solomon's seal, with an icon from the Breton flag. The owners, originally from Brittany, wanted to incorporate an icon which represented the combination and interaction of both cultures.
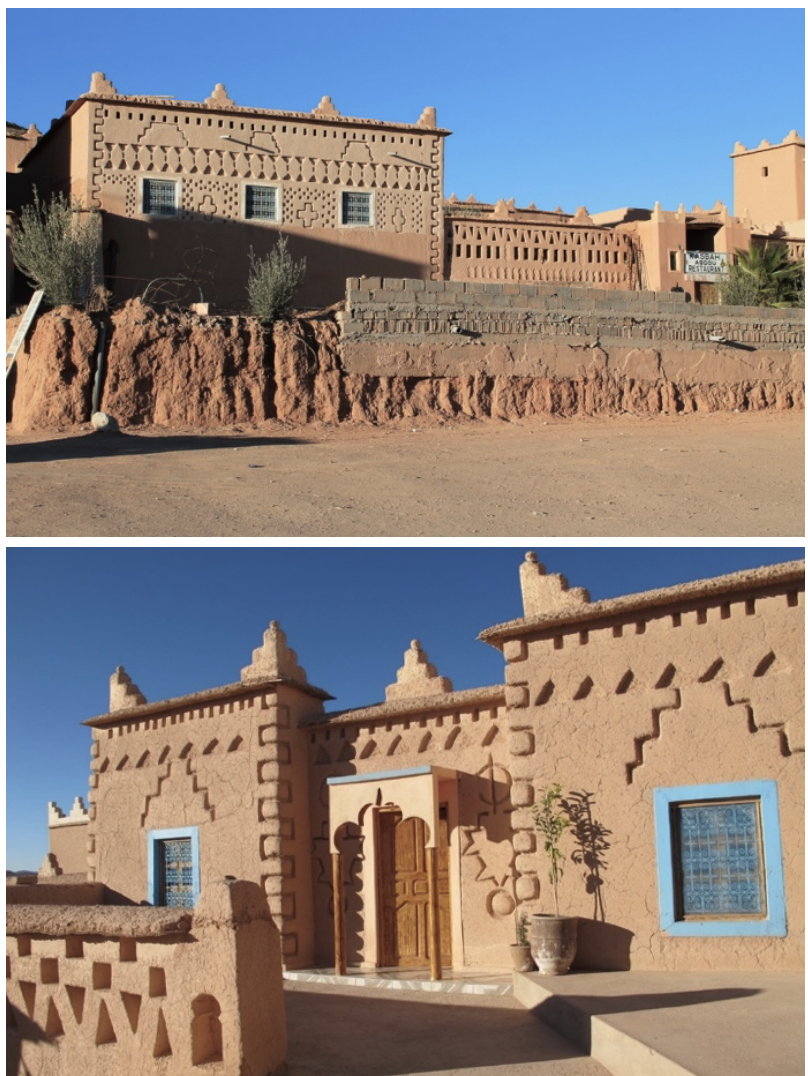

Figure 14 and 15. "Kasbah Abdou" (Source: TripAdvisor).

The maison d'hôtes "Kasbah Agoulzi" (Figure 13), an initiative which in this case is promoted by a French citizen who has lived in Morocco for the last two decades, used traditional techniques which imitate the form of local fortified dwellings. Local builders were entrusted with the design and selection of decorative elements. The walls are rammed earth on the lower levels and adobe on the upper ones, while the whole building has a final rendering of earth and straw, incorporating a wide selection of decorations introducing geometrical symbols and elements. The building has an unusual unique element: small projecting balconies on the first floor, with small glazed Arab tile roofs in green which are reminiscent of "Kasbah Taourirt" in Ouarzazate. This building aims to imitate the traditional building type, displaying an extensive decorative repertoire to folklorize the whole building, and make it more appealing to tourists.

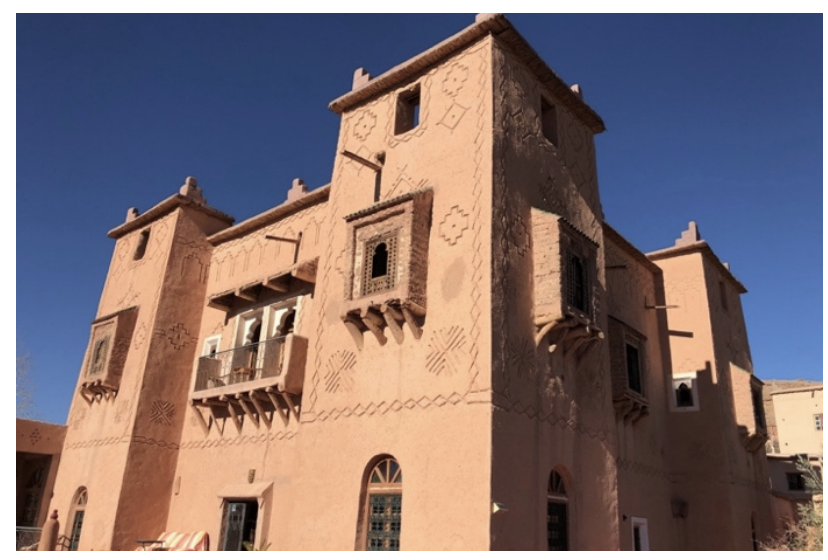

Figure 13. "Kasbah Agoulzi”, Tabarkhacht.

The maison d'hôtes "Kasbah Abdou" (Figures 14-15) is made up of a group of simple earthen constructions to which geometrical friezes had been added, both in rendered earth rendering and adobe.

This complex is visible from the busy "Kasbah Route" (N-10) and its elaborate staging is appealing to tourists. In this case, the minimal form of the corner towers (Figure 15) plays slightly with volumes on the façade.

The maison d'hôtes "Dar Timitar Vallée des Roses" (Figure 16) was built in earth also imitating a fortified dwelling, albeit with an excessively high height-width ratio, both in terms of volume and the height of the towers. The upper third of the façades incorporates geometrical decoration made using adobe, and it is worth highlighting the depth of the motifs, more characteristic of other valleys. The accommodation complex is completed with annex buildings with reinforced concrete structures and cement block enclosures, with surfaces treated to resemble earthen constructions and highly elaborate decorative motifs.

In its construction, the "Gîte Assafar" (Figure 17) tourist accommodation combines traditional materials such as wood and reeds with modern cement blocks and reinforced concrete for the main structure. The Gite takes the form of a traditional building with corner towers, although this is purely decorative it simulates different volumes going in and out of the façade.

The decoration uses bare bricks around the windows, which are not traditional. The decorative motifs are achieved by removing the final rendering layer to leave the wall visible.

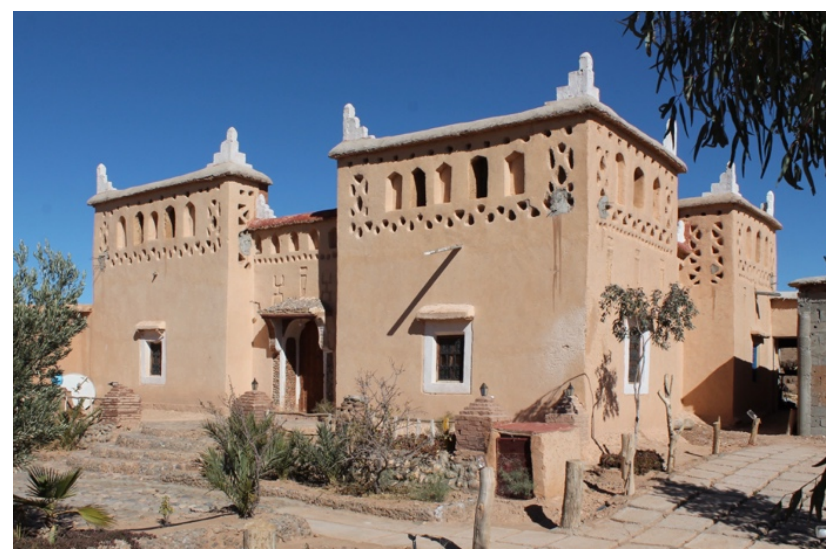

Figure 16. "Dar Timitar Vallée des Roses", Tabarkhacht. 


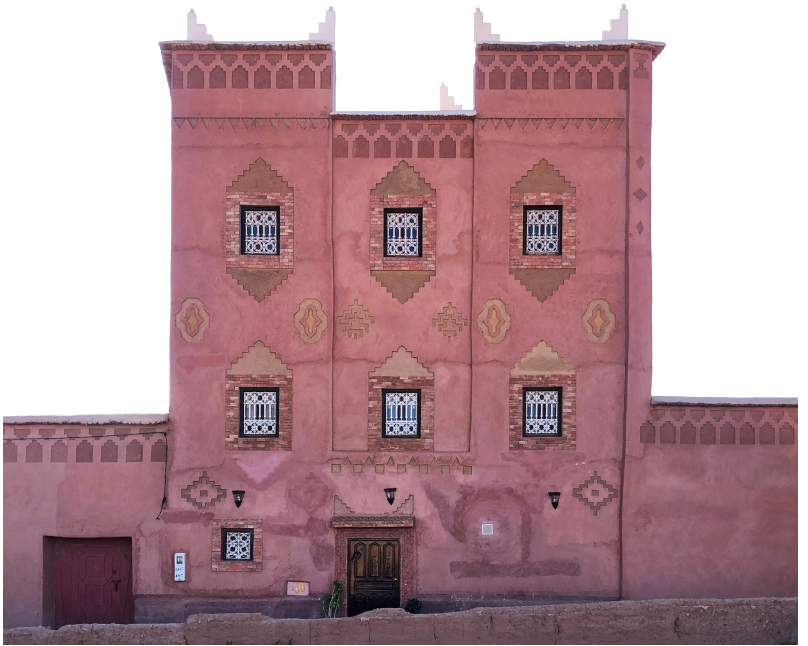

Figure 17. "Gîte Assafar", Ait Khyar.

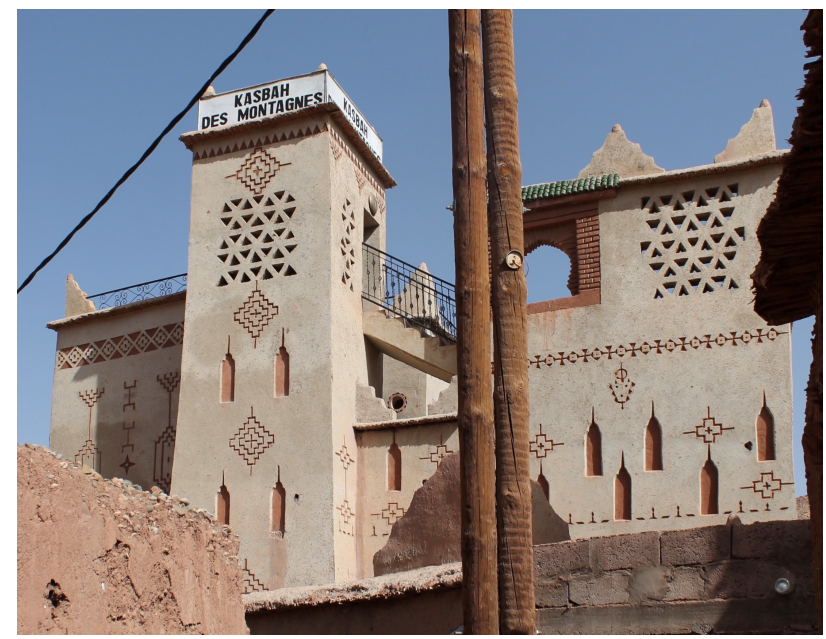

Figure 18. "Kasbah des Montagnes”, Bou Taghrar.

The tourist accommodation "Kasbah des Montagnes" (Figure 18 ) is located at the heart of Bou Taghrar, and is a compact nucleus made up almost exclusively of earthen constructions, including several high-quality fortified dwellings. The volumetric composition and decorative repertoire of the building competed with the traditional structures present. The decoration includes glazed Arab tile and horseshoe arches in bare brick, elements which are not found in the region. Thus the free placement of decorative motifs is not traditional. The building features a tower centred on one of the façades, in the part most visible from the urban setting, aiming to give a fortified appearance.

The maison d'hôtes "Riad Bérbere" (Figure 19) is one of the first examples of tourist accommodation in the Mgoun valley. The concrete building emulated the form of historic buildings, as well as the use of decorative elements and the colour of the façade, rendered in coloured mortar.

Decorative resources introduced such as the polylobed arches, are not part of the local tradition, although the building features panels with rhomboid-shaped formal elements seen in a tighremt in the same town. The building is in a historic setting surrounded by heritage buildings which it competes with in terms of its presentation in traditional form and in the development of decorative elements.
The maison d'hôtes "Kasbah Tialouite" (Figure 20) stands out on the road along the valley of Mgoun. The building features an interpretation of symbols and formal elements of the decorative tradition of the valley. It presents various colours on each of its façades in vertical strips, imitating corner towers and finished off with a wall on the terrace crowned with merlons with the traditional staggered pyramid shape.

The decorations incorporate a limited repertoire of elements in sgraffito on the façades, with geometrical drawings from the imagery of the Mgoun valley, albeit out of context and with unusual placements, such as the vertical strips which go from the base to the cornice line. It is also decorated with rendering imitating adobe pieces which have become detached and fake arch-shaped openings.

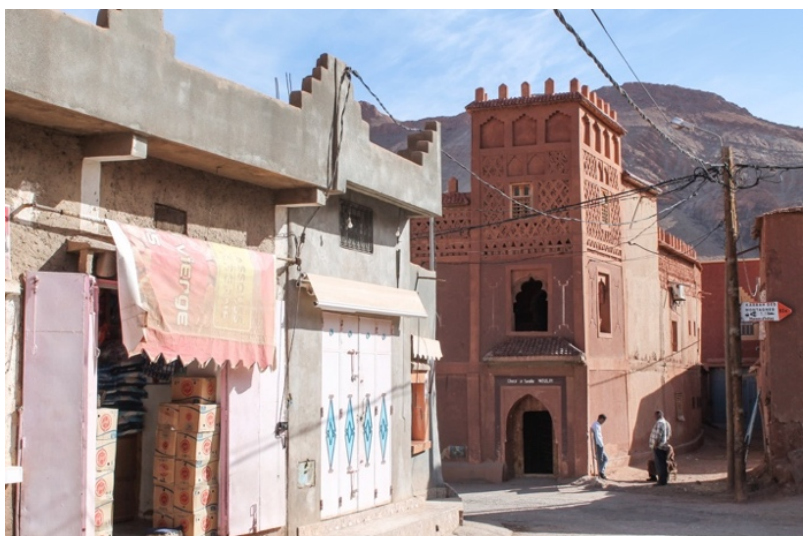

Figure 19. "Riad Bérbere Boutaghrar”, Bou Taghrar.

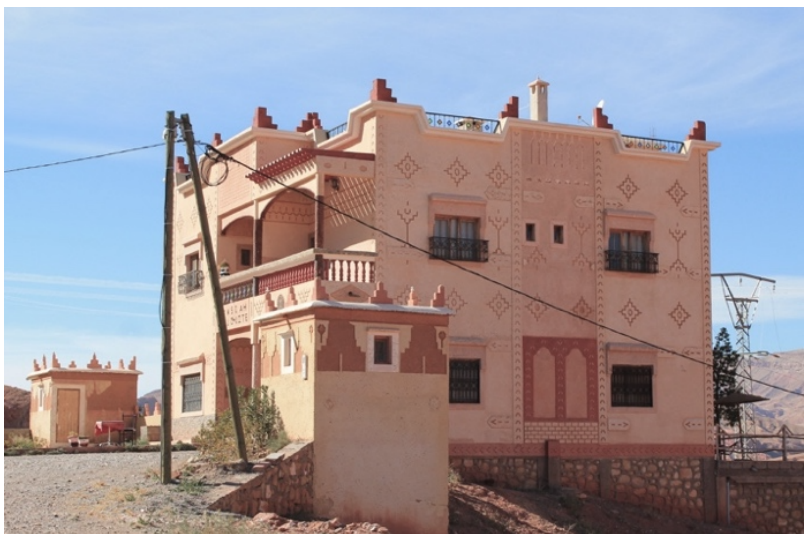

Figure 20. "Kasbah Tialouite”, Hdida.

\section{CONCLUSIONS}

As a major part of the visitor experience, the architectures of tourism play a key role in the transmission of local culture and the projection of the identity of specific regions. As seen in the case studies, tourism can become a dynamic force for the promotion of the cultural heritage of a territory and its local identity values, contributing to its conservation and survival. However, tourist activity can also project simplistic and homogeneous images which do not distinguish the true individual features which vary from community to community. Inevitable phenomena for the redefinition of identity also occur in the new architectures of tourism, when resorting to an iconography and languages which establish links with the past and references to history, adopting a style which imitates the repertoire of traditional architecture. In the case of the pre- 
Sahara valleys of the High Atlas in Morocco the points of reference are the tighremt or kasbah, which appear in the name of most of the examples of dwellings analysed, even when these are recent constructions unconnected to traditional typology.

The use of the decorative repertoire of traditional architecture in the valleys of the High Atlas started to wane in the mid 20th century and practically disappeared for over fifty years, although it is now on the rise in tourist architecture. The new iconography has invented or reinvented new decorative repertoires: innovative geometrical figures, symbols or letters from the Amazigh alphabet, a mix of Amazigh and Arab motifs, or local combinations with other cultural or aesthetic contexts. In most cases these decorations had never been used for façades, but they are now the manifestation of this new cultural reality (Figure 21). The phenomenon also includes drawings or symbols which used to be exclusively found decorating rugs and tapestries, metalwork and ceramics.

These new patterns which spread a more standardized and deterritorialized style can blur the true values and singularities of a place. The pre-Sahara region covers a vast territory, historically occupied by different tribes with individual styles and distinct repertoires in terms of form and decoration. The loss of this diversity is irreparable and entails the disappearance of the true identity values of the region.

This new iconographic language which alters the icons of tradition is used as a resource to generate an illusion, producing a superficial image by recreating a traditional building or setting. In short, these are evocative scenarios which present a consumer product to satisfy demand and meet tourist expectations. This confusion is confirmed with comments on these new forms of accommodation left by tourists on travel platforms such as TripAdvisor or Booking: "picturesque hotel"; "this establishment was an old kasbah"; "traditional decoration in the Berber style"; "authentic construction"; "Berber design and atmosphere"; and "fantastic extremely picturesque kasbah".

However, accepting that cultural expressions are changing and evolve with time, we should question the extent to which this phenomenon for profuse decoration is due to cultural transformation, the resurgence of the Berber movement and aesthetic, the inevitable acculturation or the simple response of tourist developers to the demands of potential customers. Could tourist development eventually jeopardize and compromise the appeal of the environment and identity of the tourist destination itself? Striking a balance between this development and maintaining traditional structures could be the solution.

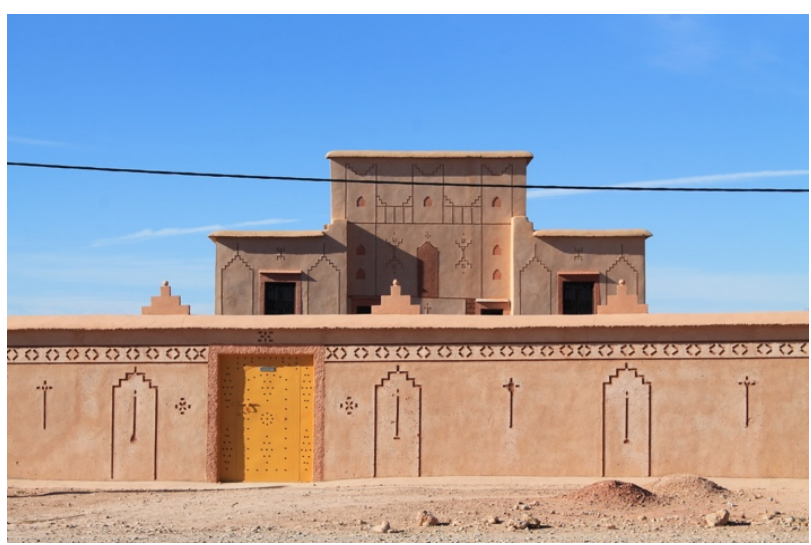

Figure 21. Contemporary dwelling in Aït Khyar, Mgoun.

\section{ACKNOWLEDGEMENTS}

We express our gratitude to Roger Mimó (Hotel Tombouctú), Juan de Dios Romero (Kasbah Ait Ben Moro), El Mostapha Hamdaoui (Dar Jnan Tioura), Arlette Faven (Maison d'hôtes Agoulzi), and Aziz Boullouz (Kasbah Assafar), as well as the owners and managers of the tourist accommodations that were visited on the development of this research. We would also like to thank all the members of the association "LOCAL LOGICS: Architecture and Cooperation" from the School of Architecture of Málaga University. All of them were interviewed during the fieldwork carried out in the framework of the doctoral thesis of the lead author of this paper.

The research is also related to the R\&D\&I project "RISK-Terra. Earthen archtecture in the Iberian Peninsula: study of natural, social and anthropic risks and strategies to improve resilience" (RTI2018-095302-B-I00), a research project funded by the Spanish Ministry of Science, Innovation and Universities.

\section{REFERENCES}

Díaz, L., García-Alcántara, M.A., Natoli, D., 2012. Contemporary earth houses and evolution models in the Mgoun Valley, Morocco. Rammed Earth Conservation. Taylor \& Francis Group, Londres, 499-504.

Jacques-Meunié, D., 1962. Architectures et habitats du Dadès: Maroc présaharien. París: Librairie C. Klincksieck.

López-Osorio, J.M., Montiel Lozano A., Martín Codes U., 2012. Rammed-earth construction in Southern Morocco: A reappraisal of the technology. Rammed Earth Conservation. Mileto, Vegas \& Cristini (eds). Taylor \& Francis Group, London. 169-174.

Mimó, R., 1996. Fortalezas de barro en el sur de Marruecos. Madrid: Compañía literaria.

Natoli, D., Vacas, A., García-Alcántara, M. A., Díaz, L., 2015. The phenomenon of tourism. Redefining architecture and landscape in southern Morocco. Vernacular Architecture: Toward a Sustainable Future. Taylor \& Francis Group, Londres, 537-541.

Oiry-Varacca, M., 2014. Quand le tourisme recompose les identités collectives: etude de projects touristiques 'alternatifs' dans les Atlas marocains. Tesis doctoral. Universidad de Genova.

Palou, S., Mancinelli, F., 2016. El turismo como refractor. Quaderns de l'Institut Català d'Antropologia, Sèrie monograàfics, n. 32, Diàlegs d'antropologia i turismo. Etnografies i debats contemporanis. Pollen editions, Barcelona, 5-28.

Popp, H., 2008. La 'Route des Kasbahs' - un produit touristique du Maroc Présaharien. Les pays du Maghreb. Contributions de la géographie humaine allemande. 31ème Congress International de Géographie à Tunis, 68-77.

Terrasse, H., 1938. Kasbas berbères de l'Atlas et des oasis. Paris: Editions des Horizons de France. 